\title{
O ESPAÇO DO LÚDICO, DO JOGO E DA DANÇA NA ESCOLA: UMA PROPOSTA DE FORMAÇÃO CONTINUADA DE PROFESSORES
}

\author{
MOYA, Leisi Fernanda ${ }^{1}$ \\ WALTER, Flávia ${ }^{2}$
}

\section{INTRODUÇÃO}

Quando se fala em brincadeira e escola, parece que estamos falando de duas coisas antagônicas, pertencentes a mundos distintos, no qual uma não pode coabitar o mesmo espaço que a outra. Escola é coisa séria, não é brincadeira! Estudar é algo importante, é preciso aprender, não sobra tempo para brincar! O brincar, muitas vezes, fica restrito ao momento do recreio ou às aulas de educação física. A concepção de que o ambiente escolar, para tornarse um espaço de ensino-aprendizagem sério, deve deixar de lado a brincadeira e o lúdico talvez não seja condizente com as inúmeras pesquisas que indicam a importância destes no desenvolvimento dos sujeitos, em especial, das crianças.

$\mathrm{Na}$ rotina escolar atual, o que se percebe é que cada vez menos se brinca. O que estaria impedindo que o lúdico, a brincadeira, a diversão estejam mais presentes na sala de aula? Acreditamos que grande parte da responsabilidade esteja na formação dos professores, em que o aprendizado sobre a importância do lúdico e de estratégias de ensino-aprendizagem lúdicas não estejam sendo discutidas e vivenciadas com a ênfase necessária. Surge, pois, outra preocupação recorrente nas pesquisas contemporâneas, que diz respeito à formação profissional docente, tanto inicial quanto continuada.

Argumentar sobre a importância da formação continuada não é novidade, diversos estudiosos já defendem essa necessidade há tempos. Os pesquisadores Palma Filho e Alves (2003), no artigo intitulado "Formação continuada: memórias" fizeram um breve relato histórico recordando que foi a partir de 1970 que a formação continuada passou a ser institucionalizada com a Lei Federal n. 5692, de 11 de agosto de 1971. Eles relataram que, na época,

\footnotetext{
${ }_{1}^{1}$ Instituto Federal Catarinense - Campus Camboriú, email: leisi@ifc-camboriu.edu.br

${ }^{2}$ Instituto Federal Catarinense - Campus Camboriú, email: flaviabroto@ifc-camboriu.edu.br
} 
tais formações eram conhecidas como treinamento, capacitação e reciclagem. Contudo, tais programas de aperfeiçoamento eram criticados, pois estavam distantes dos problemas reais que os professores tinham na época, já que não eram cursos pensados nos alunos mais carentes e que estavam passando a frequentar a escola por medidas que democratizavam as ofertas de vagas. Desde então, os autores do artigo ressaltaram que professores das universidades começaram a pôr em questão os motivos que interferem na formação inicial e continuada dos professores. Tais pesquisadores tentam construir alternativas que possam elevar a qualidade dos diferentes níveis de ensino através de projetos de formação.

Nós, professoras do Instituto Federal Caterinense - Campus Camboriú (IFC-CC) comungamos com esta práxis e por isso resolvemos relatar uma proposta de formação continuada de professores que temos desenvolvido em nosso campus desde 2011. O enfoque do curso de formação, elaborado por professores de diferentes áreas de conhecimento, é ampliar a discussão e a reflexão sobre a importância de atividades lúdicas como instrumentos de ensino-aprendizagem. Compreendemos como uma problemática o fato da maioria dos cursos de graduação em licenciaturas optarem por uma formação mais teórica, com poucas atividades voltadas para vivências práticas. A falta dessa experiência pode acarretar a insegurança por parte dos professores que, por consequência, não se sentem qualificados suficientemente para trabalharem com atividades diversificadas e lúdicas nas salas de aula.

A sociedade do século $X X$ e $X X I$ tem exigido que os profissionais estejam capacitados, preparados para o exercício da profissão, tendo assim mais habilidades em lidar com as pessoas, com versatilidade, criatividade, equilíbrio e espírito de inovação. Diante dessas exigências, um novo processo de formação profissional vem sendo deslumbrado, mesmo que timidamente, por meio da revisão e da adequação do já existente, para que, assim, seja possível atender as necessidades do atual mundo do trabalho (KULLOCK, 2000).

Sabemos que nem sempre é muito simples a participação em cursos de formação continuada. Os motivos para a não participação podem ir desde o financeiro, excesso de carga-horária que, consequentemente, provoca falta do tempo livre, até mesmo a oferta de cursos com temáticas 
desinteressantes/ repetitivas ou que não contemplem as necessidades de todos. Pensando nessas dificuldades, assim como na importância do fomento de projetos e programas relacionados à formação continuada e também no papel da extensão nos Institutos Federais de Educação é que elaboramos um projeto voltado à formação continuada para os professores de nossa região. Este projeto teve início graças a um programa interno do IFC-CC, de incentivo a pesquisa e a projetos de extensão.

O seu objetivo principal é interligar as atividades de ensino e pesquisa às demandas sociais locais. Como objetivo específico, procuramos proporcionar aos professores e aos acadêmicos de licenciaturas da nossa região uma capacitação voltada às atividades lúdicas no processo ensinoaprendizagem. A justificativa deste é, justamente, possibilitar a ampliação do conhecimento acadêmico, cultural e historicamente construído, bem como permitir que o IFC-CC abra suas portas à comunidade local, estendendo possibilidades de novas práticas educativas a professores e futuros profissionais. A problemática que o norteia é: "Como tornar o processo ensinoaprendizagem mais lúdico e significativo para os alunos?". Com o propósito de contribuir com o processo de formação de professores e de compartilhar nossas experiências e conhecimentos pessoais sobre a dança, os jogos, o lúdico e o processo ensino-aprendizagem lançamos a proposta deste projeto.

\section{FORMAÇÃO CONTINUADA DE PROFESSORES}

De acordo com Nóvoa (apud Kullock, 2000), eis o grande desafio da modernidade: a formação docente. Dessa maneira, o autor argumenta que não há desafios nem reforma educativa sem que haja em conjunto uma renovação pedagógica, ou seja, sem uma adequada formação de professores. Sabemos que os cursos de graduação não são os únicos responsáveis pelos saberes docentes, pois estes advêm também do conhecimento proveniente das experiências vividas como acadêmico, dos saberes adquiridos na atuação prática da docência, da graduação, dos cursos de especialização e das demais possibilidades de formação continuada.

Corroboramos com as ideias de Costa (1994) quando menciona que a aprendizagem da profissão docente é um processo que o professor realiza e 
aperfeiçoa durante toda a vida, compreendendo a formação de professores como um grande continuum que integra períodos de formação acadêmica e atuação profissional, ou seja, conhecimentos teóricos e práticos. É imprescindível o professor manter-se atualizado na área de conhecimento em que atua, visto que, sendo sua própria natureza do saber pedagógico, alçada da práxis, o processo é histórico e inacabado.

Para Zeichner (2003), a formação de professores deve sofrer uma reforma educacional, rejeitando o modelo tecnocrático e aproximando o mundo para todos, ou seja, que possa satisfazer aos filhos de todos. Desse modo, o pesquisador enfatiza a importância de haver professores que sejam genuínos educadores e que possam diminuir a distância na qualidade da educação dos diferentes grupos sociais, apoiando a preparação de educadores reflexivos para uma educação centrada no aluno. Os educadores, segundo o autor, só ensinarão de uma forma mais democrática e centrada no aluno quando passarem por uma transformação conceitual sobre o seu papel e sobre a natureza de ensinar e aprender.

A escola é hoje e sempre será um espaço propício para uma reflexão sobre o ensinar e o aprender, mas, muitas vezes, acaba esquecendo sua real função quando "aprisiona os conteúdos em grades curriculares", como afirmou Frigotto (2015) em uma fala no 9ํㅗㄴ Seminário Nacional de Educação do Sinasefe ${ }^{3}$. Na percepção de Charlot (2003, p.27), "a relação com o saber e com a escola é uma relação social", portanto, tal relação é feita por um indivíduo que tem consciência sobre a sua posição de dominado, buscando dar um sentido de mundo e adaptando-se. Assim, "a posição social produz seus efeitos pelo desejo, pela atividade, história do sujeito, ela não determina direta ou indiretamente o sucesso ou o fracasso escolar" (id.). Dessa forma, a relação com o saber e com a escola é, concomitantemente, social e subjetiva. $O$ pesquisador ressaltou que para que o aluno se aproprie do saber é preciso que o aluno estude, envolva-se em atividades intelectuais e mobilize-se intelectualmente. Tal apropriação discente só ocorre se ele tiver o desejo de saber e aprender ao mesmo tempo. Na sequência, o autor acrescentou que "do

\footnotetext{
${ }^{3}$ SINASEFE - Sindicato Nacional dos Servidores Federais da Educação Básica, Profissional, Tecnológica.
} 
ponto de vista teórico, uma aula interessante é aquela em que ocorre o encontro do desejo e do saber" (CHARLOT, 2003, p.30).

Em sua pesquisa, Géglio (2006 apud Gatti, 2008) questionou os entrevistados sobre a percepção que possuíam dos cursos que fizeram e como os conhecimentos adquiridos contribuíram com a prática docente após o curso. O pesquisador identificou um discurso contraditório em alguns, ao afirmarem que não aprenderam nada, todavia, estes docentes descreveram várias aprendizagens adquiridas, seja como novos conhecimentos, seja como "rememoração" de atividades já perdidas. Assim, a pesquisadora Gatti (2008) justificou que "a educação continuada foi colocada como aprofundamento e avanço nas formações dos profissionais" (p.62). Com isso, compreendemos que tal aprofundamento surgiu da necessidade da ideia de atualização constante, das mudanças no mundo do trabalho e, consequentemente, devido às mudanças nos conhecimentos e nas tecnologias.

\section{O LÚDICO E O PROCESSO DE ENSINO-APRENDIZAGEM ESCOLAR}

O eixo norteador do projeto é a possível relação entre o lúdico e o processo de ensino-aprendizagem, compreendendo o lúdico não como um contraponto a seriedade, ou ao que culturalmente se denomina como sério, mas sim como meio facilitador do aprendizado. Ao considerarmos que o brincar é uma atividade inerente ao ser criança e que por meio da brincadeira ela desenvolve diversas habilidades, como a comunicação e interação com demais crianças ou com adultos, a criatividade e a imaginação, a capacidade de elaborar ideias, criar situações e resoluções de problemas, ou seja, suas habilidades cognitivas, ao expressar-se, expor seus sentimentos, entre tantas outras, compreendemos a importância da brincadeira e de situações em que a ludicidade possa ser aflorada.

A raiz etimológica do termo vem do latim ludus e pode-se atrelar seu significado ao jogo, brinquedo, diversão. Já a ludicidade relaciona-se com uma necessidade corporal, um estado de felicidade, de prazer, de alegria, algo que nos possibilite um bem estar. No entanto, não podemos esperar que o lúdico ocorra apenas em atividades espontâneas, sobretudo na escola. É preciso 
propiciar momentos e espaços para que as atividades lúdicas possam ocorrer, ou seja, para que o ambiente e a postura lúdica possam se instaurar.

Para Luckesi, (1998), a atividade lúdica é capaz de nos possibilitar uma participação plena, em que nos envolvemos de modo integral, alegre, flexível e de modo saudável. Em suas palavras: "a atividade lúdica não admite divisão; e, as próprias atividades lúdicas, por si mesmas, nos conduzem para esse estado de consciência" (p. 2). Portanto, é preciso ter claro que nem toda a atividade é lúdica e que nem sempre o que é lúdico para um é para outro, pois depende de fatores internos, do quanto me envolvo e me interesso pela atividade. Tal condição implica um desafio para as atividades educativas, visto que na escola nos deparamos com sujeitos singulares, com habilidades e interesses diversificados, com os quais as atividades propostas podem agradar ou não. Esta consciência é necessária e nos proporciona refletir criticamente sobre nossas possibilidades e limites enquanto educadores.

Brougère $(2004 ; 2010)$ confirma que existe uma cultura lúdica e diferentes modos de brincar e de se relacionar com a brincadeira, dado que estamos inseridos em um contexto em que a cultura não é algo singular, mas plural. De acordo com ele, existe uma individualização da cultura, tendo em vista que nem todos compartilham os mesmos elementos da cultura lúdica de uma mesma geração, existe ainda uma diferença quanto ao gênero, ou seja, nas brincadeiras de meninos e de meninas, assim como na vida de cada um, o que torna a experiência lúdica diversa.

\section{JOGO, BRINCADEIRAS E DANÇA COMO ESTRATÉGIAS PARA UM ENSINO PERMEADO PELA LUDICIDADE}

Compreendendo a importância do jogo, da brincadeira, da dança e a estreita relação destes com o lúdico, entendemos que eles podem ser defendidos como recursos para uma estratégia de ensino lúdico.Tais defesas são ocasionadas, entre outros motivos, a partir da contribuição com o processo de interação social, com a capacidade de desenvolvimento motor, cognitivo e, principalmente, afetivo.

De acordo com Oliveira (2009, p. 17), o jogo contribui com a aprendizagem uma vez que "representa uma prática significativa, pois oferece 
flexibilidade, desafio e exigência de raciocínio", o que nos possibilita inferir que o jogo é importante no processo ensino-aprendizagem. Kishimoto $(1994,1998)$ afirma que o jogo não é algo inato ao ser humano, mas sim algo que faz parte de uma construção social, ou seja, não nascemos sabendo jogar, precisamos aprender. Da mesma maneira o professor não nasce professor, precisa aprender, e esse aprender implica também aprender a jogar e saber utilizar o jogo como uma de suas estratégias de ensino.

O jogo pode ser utilizado como uma possibilidade de se trabalhar com conceitos de cooperação, inclusão, formação integral do sujeito, expressão corporal, ritmo, entre outros. A prática educativa com jogos pode ser uma excelente ferramenta a favor do professor em sala de aula, auxiliando também no trabalho das quatro habilidades linguísticas: ouvir, falar, ler e escrever. Com isso, outro objetivo do curso é vivenciar atividades lúdicas envolvendo a temática de línguas (português/inglês/espanhol), visando o melhor aproveitamento destas, tornando-as mais significativas para os estudantes.

No campo teórico da psicologia, um dos autores que contribuiu significativamente com estudos sobre a importância do lúdico e da brincadeira para o desenvolvimento e a aprendizagem da criança foi Vygotsky. Para esse autor, a brincadeira cria uma zona de desenvolvimento proximal, estimulando a criança a aprender conhecimentos e habilidades que ainda não domina sozinha, mas é capaz de exercer com a ajuda de outra pessoa mais capacitada.

No brinquedo, a criança sempre se comporta além do comportamento habitual de sua idade, além de seu comportamento diário; no brinquedo, é como se ela fosse maior do que é na realidade. Como no foco de uma lente de aumento, o brinquedo contém todas as tendências do desenvolvimento sob forma condensada, sendo, ele mesmo, uma grande fonte de desenvolvimento (VIGOTSKI, 2007, p. 122).

A atividade lúdica provoca importantes mudanças no desenvolvimento psíquico da criança, preparando-a cognitivamente para as próximas etapas de seu desenvolvimento. Além disso, brincar é uma maneira de incorporar os elementos da cultura na qual se está inserida e a cultura de outros povos ou localidades. Brincar também exige interação social e, por essa 
razão, a atividade lúdica também possibilita que a criança adapte seu comportamento conforme o seu contexto social.

Percebemos também que algumas manifestações corporais, como a dança, estão muito presentes na nossa cultura, seja nas letras de músicas, festas, bailes, casamentos, comemorações, entre outros, entretanto, se faz pouco presente nas escolas, salvo em situações ou dias festivos, em que as crianças são ensaiadas para se apresentar aos pais ou ao público. A dança possibilita um maior conhecimento sobre o corpo e suas possibilidades de movimento, proporciona compartilhar e vivenciar diversificadas manifestações culturais, além disso, experimentar e manifestar sentimentos, emoções. De acordo com Garcia e Haas (2006), a dança ganha um lugar de destaque na educação Grega no período que antecede à ldade Média, por meio do estímulo dado aos gregos, ela era vista como requisito social e educacional.

Concordamos com Marques (2003, 2008), quando esta menciona que as gerações que não tiveram a dança incluída em suas vidas escolares não conseguiram atribuir um sentido a dança no contexto da escola. Um dos objetivos do curso é possibilitar, por meio do jogo e das brincadeiras, estratégias de ensino que possam contribuir com ensino da dança nas escolas, permitindo um acesso mais democrático e lúdico desse conteúdo que está presente em nossa cultura corporal e que vem sendo tão pouco explorado e compreendido nas escolas.

\section{METODOLOGIA}

O curso "O espaço do lúdico, do jogo e da dança na escola: uma proposta de formação continuada de professores" tem uma carga horária aproximada de 60 horas, caracterizando-se como semipresencial. As atividades presenciais são realizadas no IFC-CC, possibilitando uma maior aproximação entre a comunidade local e o Instituto. A metodologia utilizada no desenvolvimento do projeto tem aproximações com a pesquisa qualitativa e se baseia nos princípios da pesquisa-ação, que de acordo com Thiollent (1996, p.14, apud Confortin, Berria e Santos, 2012), se realiza por meio de uma estreita associação entre uma ação ou com a solução de um problema coletivo, em que os pesquisadores e participantes estão envolvidos de modo 
cooperativo ou participativo. Portanto propomos uma maior aproximação com a comunidade e a participação desta como agente ativo nesse processo de maior qualificação e atuação docente.

São realizados em torno de seis a oito encontros presenciais, com carga horária entre quatro e oito horas cada, em que são realizadas atividades com vivências diversificadas, por professores de diferentes áreas de conhecimento, como: educação física, arte, inglês, psicologia, música e espanhol. A proposta é, por meio de estratégias de ensino como leituras, debates, análise de documentários ou filmes, vivências, elaboração de textos, elaboração de portfólios, entre outras, que os professores possam reviver atividades lúdicas que os remetam à infância para que possam relembrar e refletir sobre a importância do lúdico no processo ensino-aprendizagem.

Além das atividades presenciais, como complemento da carga horária e da formação, cada participante, ao finalizar o curso, assume a responsabilidade de entregar um portfólio ou um relatório, no qual deve constar o registro das atividades realizadas durante os encontros presenciais, o feedback sobre a apropriação de conhecimento de cada um, além da elaboração de resenhas ou resumos de textos utilizados como material de apoio durante o curso. Quando possível, os participantes também procuram aplicar as estratégias de ensino aprendidas e vivenciadas no curso em ambientes de ensino formal. Esses portfólios ou relatórios são utilizados também para avaliação do curso e levantamento de dados para realização de nossas pesquisas.

\section{RESULTADOS E DISCUSSÕES}

Durante o período em que essa proposta de formação continuada está vigente, os números de participantes e interessados vêm aumentando cada vez mais. Como hipótese, podemos atribuir esse interesse ao fato de ser um curso gratuito, ofertado aos sábados, o que facilita 0 acesso aos professores, além de uma equipe de professores que tem se dedicado e estudado para tornar esses encontros momentos lúdicos de aprendizagem e crescimento profissional, o que tem atraído adeptos. 
Consideramos que a carga horária dos encontros, embora facilite a participação e continuidade no curso, ainda é muito baixa. Acreditamos que seria necessária uma carga horária maior, fato que as avaliações dos participantes também ressaltam e confirmam. No entanto, entre alguns fatores que impedem atualmente a ampliação dessa carga horária, esta a dificuldade dos professores do curso em equilibrar a carga horária destinada ao ensino, à pesquisa e a extensão, exigências inerentes dos Institutos de Educação. A carga horária destinada a projetos de extensão ainda é muito baixa, o que dificulta esse equilíbrio. Outros fatores como a dinâmica do contexto contemporâneo e o excesso de compromissos dos próprios participantes (eventos escolares em sábados letivos, por exemplo) seriam relevantes para o impedimento do aumento dos encontros presenciais. Este é um ponto que o grupo tem analisado e tentado solucionar.

Acreditamos que há mais aspectos positivos do que negativos nessa proposta de formação continuada, as avaliações e relatos dos participantes reiteram tal observação. Destacamos trechos de relatos de dois participantes, escolhidos aleatoriamente, para que possamos dar voz também aos envolvidos nesse processo:

[...] relembrei de cantigas de roda, de brincadeiras que me remete a minha infância. Além do mais ressaltou a importância do lúdico na educação infantil e nos anos inicias do ensino fundamental (A, 2014). [...] O professor, como mediador da aprendizagem, deve fazer uso de novas metodologias, técnicas e estratégias e planejar as atividades a serem aplicadas procurando sempre incluir as brincadeiras, jogos e brinquedos em suas aulas [...] (B, 2014).

Esses relatos nos permitem compreender que os objetivos do curso têm sido atingidos e que as atividades realizadas têm cumprido com a função de afirmar a importância do lúdico na escola.

\section{CONCLUSÃO}

Acreditamos que momentos de formação como esse que nos propomos ofertar devem ser, em primeiro lugar, algo desejado a priori pelos seus participantes (professores ou ainda estudantes de licenciatura) e jamais obrigatório (semana pedagógica ou só para preencher currículo). As atividades 
feitas a partir do interesse do indivíduo acabam sendo mais significativas já que estes sujeitos estão abertos para este encontro com o saber. Consideramos que a não obrigatoriedade o torna mais atrativo, assim como a ampla variedade temática, que acaba permitindo que os professores de diferentes áreas sintamse interessados em participar.

Para concluir, reiteramos que, além de ser nossa missão como docentes dos IF's Federais nos envolvermos nas atividades de ensino, pesquisa e extensão, oferecer aos professores das redes públicas condições para a formação contínua, com acesso gratuito, é imprescindível. Ao final, não podemos deixar de destacar e parabenizar o IFC-CC, que tem aberto suas portas, disponibilizando recursos materiais e pessoais para que propostas como essa possam ser concretizadas.

\section{REFERÊNCIAS}

BROUGÈRE, Gilles. Brinquedo e cultura. 5.ed.: São Paulo, Cortez, 2004. . Entrevista com Gilles Brougère sobre o aprendizado do

brincar. Revista nova escola. ABRIL, março de 2010, páginas 32 a 35.

CHARLOT, Bernard. O sujeito e a relação com o saber. In: BARBOSA, Raquel Lazzari Leite (Org.). Formação de educadores: Desafios e perspectivas. Editora UNESP. São Paulo: 2003.p. 23-34.

CONFORTIN, Susana; BERRIA, Julia; SANTOS, Saray Giovana dos. Pesquisa Ação e Pesquisa Participante. In: SANTOS, Saray Giovana, MORETTI-PIRES, Rodrigo Otávio (org.). Métodos e Técnicas de Pesquisa Qualitativa aplicada à Educação Física. Florianópolis: Tribo da llha, 2012. p. 123-141.

COSTA, Francisco Carreiro da. Formação de professores: objetivos, conteúdos e estratégias. Revista Educação Física/UEM, v.5, n.1, Maringá, 1994.

FRIGOTTO, Gaudencio. "Rede Federal de Educação Básica, Profissional e Tecnológica: onde estamos e o que queremos?". Bahia: Palestra de abertura do 9o Seminário de Educação do SINASEFE. 23 abril, 2015.

GARCIA, Ângela; HASS, Aline Nogueira. Ritmo e Dança. 2.ed. Canoas: ULBRA, 2006.

GATTI, Bernardete A. Análise das políticas públicas para formação continuada no Brasil, na última década. Revista Brasileira de Educação v.13 n.37, jan/abril, 2008. 
KHISHIMOTO, Tizuko M. O jogo e a educação infantil. São Paulo: Cengage Learning, 1994.

KISHIMOTO, Tizuko M. (Org.) - O brincar e suas teorias, São Paulo: Pioneira Educação, 1998.

KULLOCK, Maisa Gomes Brandão. As exigências da Formação do professor na atualidade. Maceió: Edufal, 2000.

LUCKESI, Cipriano. Avaliação da aprendizagem escolar. 8 ed. São Paulo: Cortez, 1998.

MARQUES, Isabel A. Dançando na Escola. São Paulo: Cortez, 2003.

MARQUES, Isabel A. Ensino de dança hoje: textos e contextos. São Paulo: Cortez, 2008.

OLIVEIRA, Francismara N. de; BAZON, Fernanda Vilhena M. (org.). (Re) significando o lúdico: jogar e brincar como espaço de reflexão. Londrina: EDUEL, 2009.

PALMA FILHO, João Cardoso; ALVES, Maria Leila. Formação continuada: memórias. In: BARBOSA, Raquel Lazzari Leite (Org.). Formação de educadores: Desafios e perspectivas. Editora UNESP. São Paulo: 2003.p. $279-296$.

VIGOTSKI, Lev Semenovich. A formação social da mente: o desenvolvimento dos processos psicológicos superiores. 7 ed. São Paulo: Martins Fontes, 2007.

ZEICHNER, Kenneth M. Formando professores reflexivos para a educação centrada no aluno: possibilidades e contradições. In: BARBOSA, Raquel Lazzari Leite (Org). Formação de educadores: Desafios e perspectivas. Editora UNESP. São Paulo: 2003. 